\title{
Study on Growth, Structural, Mechanical and Electrical Properties of L- Lucinedoped NSH Single Crystals
}

\author{
T.Benila $^{1}$, S.Perumal $^{2}$ \\ ${ }^{1}$ Sivanthi Aditanar College Pillayarpuram, ${ }^{2}$ Physics Research center, S.T Hindu college, Nagercoil - 629002 , \\ India.
}

\begin{abstract}
The single crystal of L- Lucinedoped NickelSulphateHexa Hydrate (NSH) was grown from slow evaporation technique for different molar concentrations, viz., (0.2 to 1 mole\% in steps of 0.2 ). The crystallinty, cell parameter and cell volume of the grown single crystals was estimated by powder X-ray diffraction studies. The mechanical power of the crystals wasstudied by Vicker's micro hardness testing. The electrical study was carried out for both pure and doped NSH crystals.

Key words: Crystal growth, X-ray diffraction, Electrical, Optical properties.
\end{abstract}

\section{INTRODUCTION}

Crystal growth and characterization is one of the important research areas in science and technology. Developments in technology have stimulated the importance of discovering new materials and modifying the already known materials. Growth of single crystals and their structural and physical characterization come under Nickel sulphatehexa hydrate (NSH) crystals are widely used for UV light filters sensors [1,2].Single crystals are important materials for electronic, optical devices and laser crystals [3,4]. Recently reported crystals are Rubidium Nickel SulphateHexahydrate (RNSH), Ammonium Nickel SulphateHexahydrate (ANSH), PotassiumNickel SulphateHexahydrate (KNSH), etc. [5-7]. In the present systematic examination is single crystal of pure Nickel SulphateHexa Hydrate L-Lucine doped Nickel SulphateHexa Hydrate was grown by slow evaporation procedure.The grown crystals were characterized by powder X-ray diffraction and mechanical studies. The title compound has good dielectric behaviour and all are indicating an increase electrical parameter viz. $\sigma_{\mathrm{ac}}, \varepsilon_{\mathrm{r}}$ and $\tan \delta$ with the increase of temperature.

\section{CRYSTAL GROWTH}

Crystal growth is a important stage of a crystallization process and made up of atoms, ions, or polymer strings into the typical arrangement of a crystalline Bravais Lattice.The title compound was prepared by dissolving analar grade Nickel SulphateHexa Hydrate (NSH) by means of doping it with L- Lucinein different but definite molecular ratios. We have grown pure and L- Lucinedoped crystals by the slow evaporation method at room temperature [11]. NSH crystal was doped with L- Lucinein six NSH: LLucinemolecular ratios, viz. 1:0.000, 1:0.002, 1:0.004, 1:0.006, 1:0.008 and 1:0.010.Approximate molar ratio of materials was taken using digital balance and dissolved in double distilled water. The solution of $\mathrm{pH}$ value 7 was stirred with magnetic stirrer and allowed to evaporate without disturbance. Optically good quality NSH single crystals have been grown within a time period of 7 to 14 days. Initially very small crystals appeared then grew bigger in size. Out off grown crystals, best crystals were selected for further studies and are shown in Figure1.

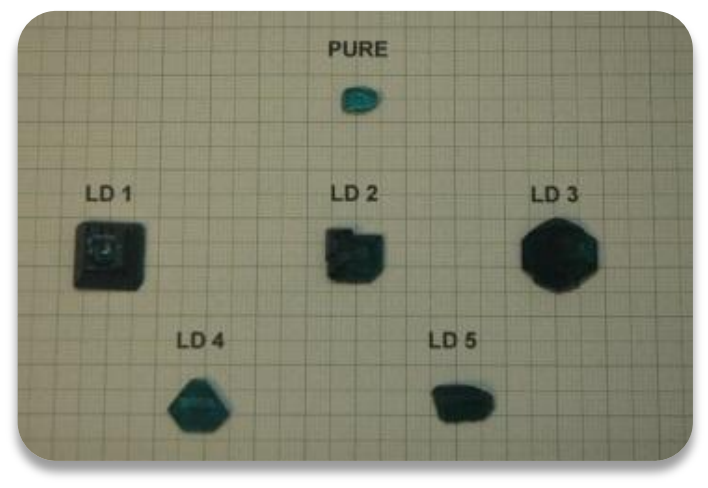

Fig1. Photograph of the grown Pure and Doped NSH crystals. 


\section{CHARACTERIZATIONS}

PXRD data were collected from powdered sample for pure and doped NSH crystals using diffractrometer. The reflections of hkl were indexed. The identification of the X-ray peaks was found byeffective methods and lattice constants were firmly decided [8- 10]. The mechanical state of the grown crystals were analysed by the Vicker'smicrohardness test which was performed using the Vivker'smicrohardness tester. The well-polished, flat faced crystals were used. The hardness test was performed for the loads varying from $25 \mathrm{~g}$ to $100 \mathrm{~g}$ and the stability of the crystals towards the external stresses was observed.The dielectric constant of the material can be measured using two probe method. The samples were cut and polished, thenecessary sides were coated with graphite to obtain a good ohmic contact with the electrodes.Using different temperature ranging $\left[40^{\circ} \mathrm{C}\right.$ to $\left.75^{\circ} \mathrm{C}\right]$ the capacitance and dielectric loss values were carried out [11] using an Agilent 4284ALCR meter for frequencies like $1 \mathrm{KHz}, 10 \mathrm{KHz}, 100 \mathrm{KHz}, 1 \mathrm{MHz}$. The dimension of the growncrystals was measured using a microscope. Air capacitances were also measured for the dimensions equal to that ofall thecrystals.

\subsection{POWDER XRD}

\section{RESULTS AND DISCUSSION}

X-ray diffraction studies of solution grown NSH crystals was carried on XPERT-PRO using X-ray CuKa radiation (1.54059340) was used. The samples were scanned in the $2 \Theta$ range of $10^{\circ}-70^{\circ} \mathrm{X}$-ray diffractogram is shown in figure2. It shows the powder X-ray diffraction pattern, the $\mathrm{d}$ - spacing of lattice planes depend on the size of the elementary cell and determine the position of the peaks. The presence of prominent Bragg's peak 2 Oangle confirms the perfect crystal line structure. The diffraction data almost matches with JCPDS data for pure NSH crystals. Table1 indicates the unit cell parameters satisfy the condition for Tetragonal system i.e., $a=b \neq c$ and $\alpha=\beta=\gamma=90^{\circ}$ from the above data and it may be concluded that the grown crystals of NSH have tetragonal system with very slight changes in the peak positions, slight change in the relative intensities, cell volume and lattice parameters and these slight changes are due to the doping of L- Lucine in NHS crystal.
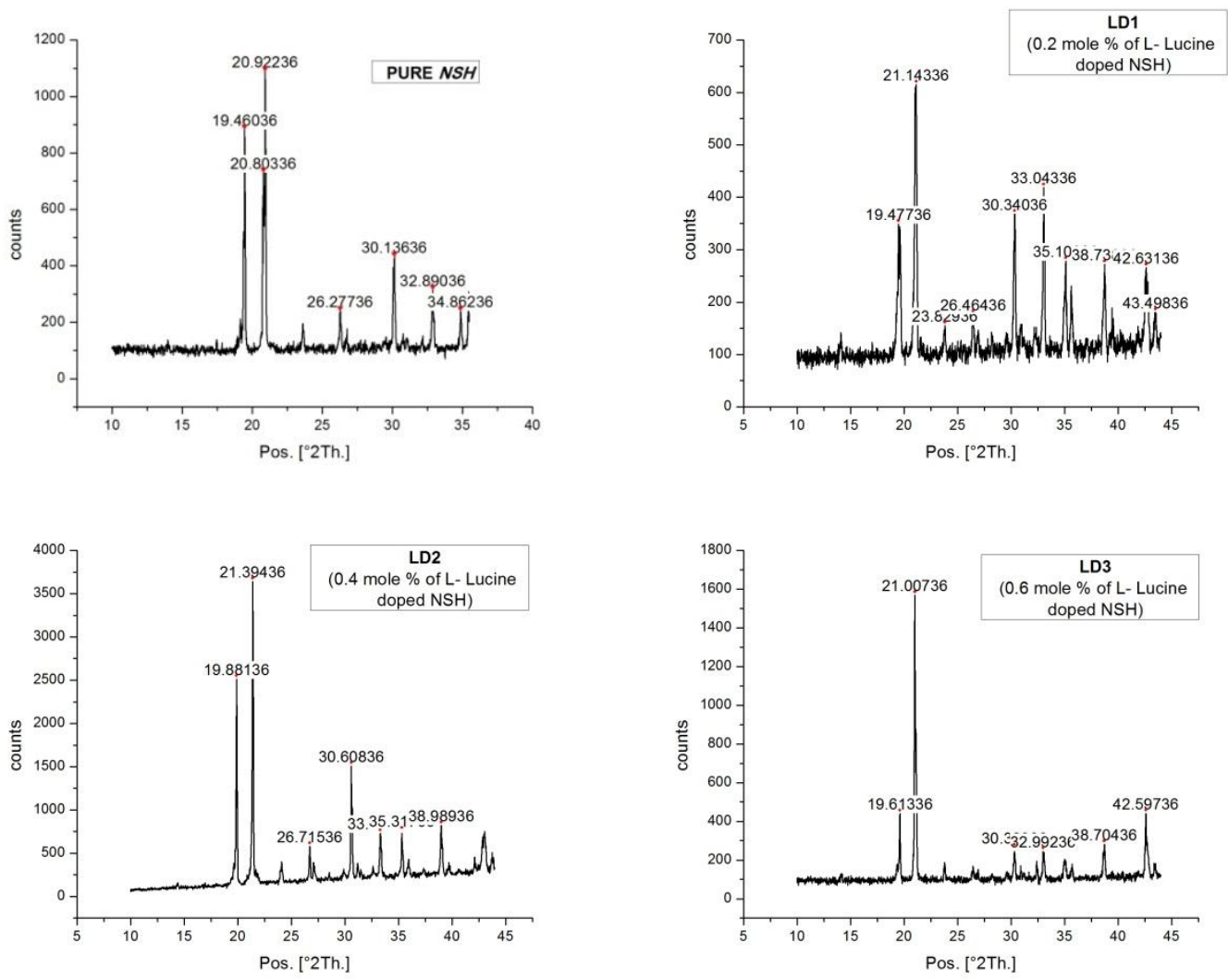

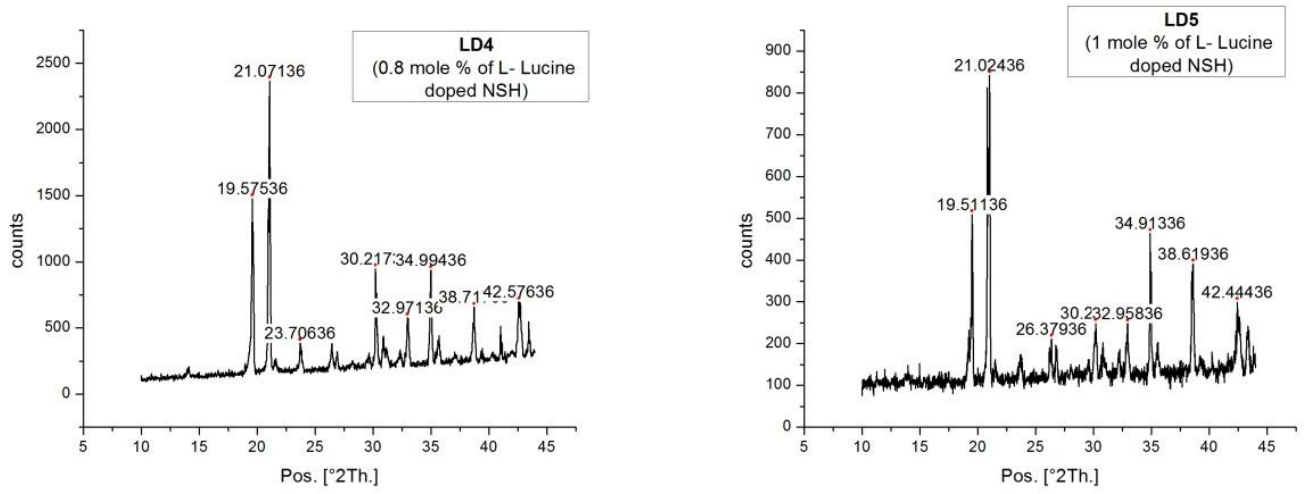

Fig2. Indexed Powder XRD pattern of pure and doped NSH crystal

Table 1 - Calculated Lattice parameter for pure and doped NSH single crystals.

\begin{tabular}{|c|c|c|c|c|c|}
\hline \multirow{2}{*}{ Samples } & \multirow{2}{*}{$\begin{array}{l}\text { Crystal } \\
\text { system }\end{array}$} & \multicolumn{3}{|c|}{ Unit cell parameters } & \multirow{2}{*}{ Volume } \\
\hline & & $a=b$ & $\mathrm{c}$ & \multirow{7}{*}{$\alpha=\beta=\gamma=90^{\circ}$} & \\
\hline Pure NSH & \multirow{6}{*}{ Tetragonal } & 6.782 & 18.266 & & 840.130 \\
\hline $\begin{array}{l}\text { LD1(0.2 mole \% of L-arginine } \\
\text { doped NSH) }\end{array}$ & & 6.801 & 18.218 & & 842.748 \\
\hline $\begin{array}{c}\text { LD2(0.4 mole \% of L-arginine } \\
\text { doped NSH) }\end{array}$ & & 6.825 & 18.006 & & 838.723 \\
\hline $\begin{array}{c}\text { LD3(0.6 mole \% of L-arginine } \\
\text { doped NSH) }\end{array}$ & & 6.545 & 18.652 & & 798.999 \\
\hline $\begin{array}{c}\text { LD4(0.8 mole \% of L-arginine } \\
\text { doped NSH) }\end{array}$ & & 6.716 & 18.078 & & 815.346 \\
\hline $\begin{array}{l}\text { LD5(1 mole \% of L-arginine } \\
\text { doped NSH) }\end{array}$ & & 6.774 & 18.256 & & 837.599 \\
\hline
\end{tabular}

\subsection{MECANICAL STUDIES}

Hardness is a measure of resistant in solid matters to various kinds of permanent shape change when a compressive force is applied. Here the applied loadis in the range from 25 to $100 \mathrm{~g}$ for indentation period of $10 \mathrm{~s}$. Hardness number $\left(\mathrm{H}_{\mathrm{v}}\right)$ was calculated using the relation $\mathrm{H}_{\mathrm{v}}=1.852 \mathrm{P} / \mathrm{d}^{2} \mathrm{Kg} / \mathrm{mm}^{2}$. It is found that the hardness number increases with the increasing load. The working hardening coefficients (n) were determined from the slopes of Log p vs. Log d plots. The values of $n$ are found to be greater than two. The $n$ values observed in the present study indicate that all the crystals grown belong to softmaterial category. This has been shown in Figure3-4 and Table2. According to Onitsch, the value of $\mathrm{n}$ should decide hard or soft material (n should below 1.6 for hard sample but above 1.6 for soft ones) [12]. Hence L-Lucine nickel sulphate crystals belongs to soft material.
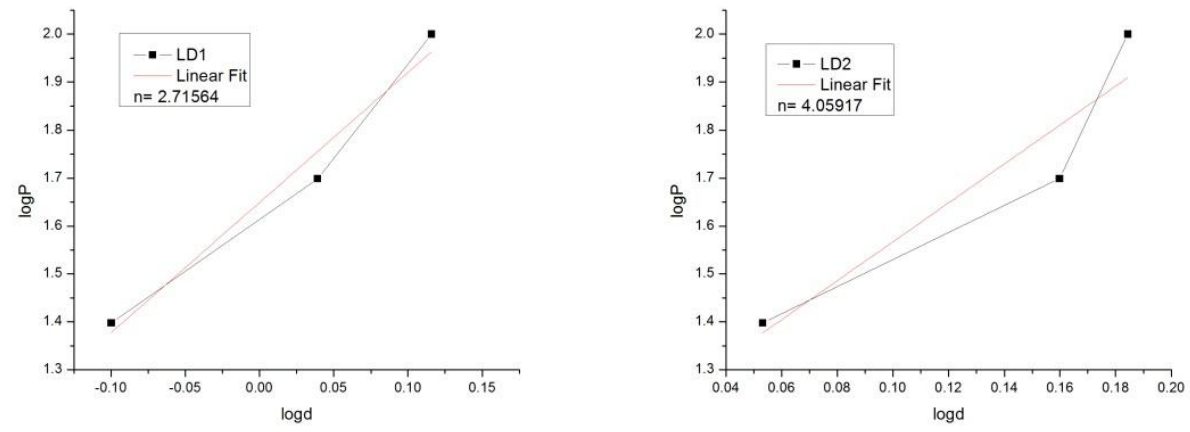

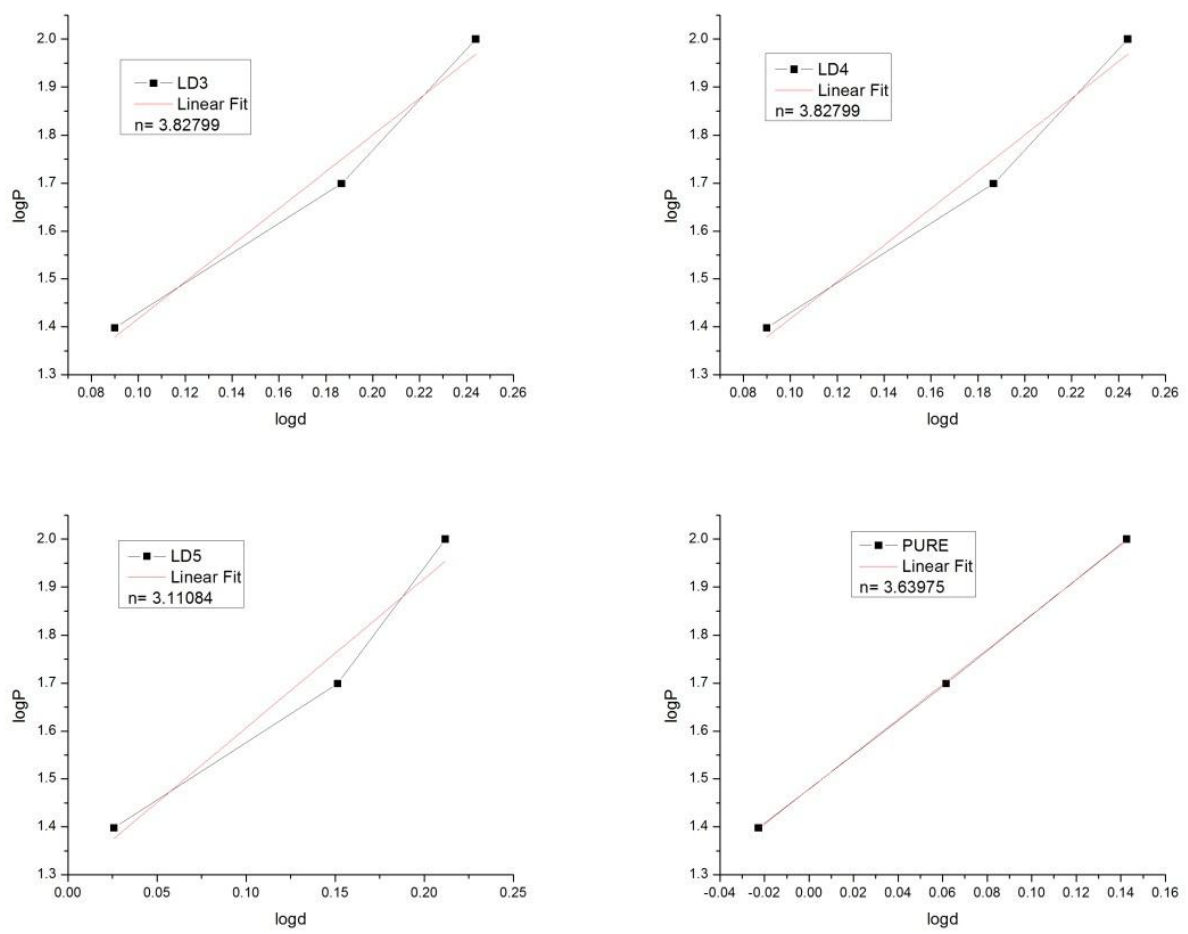

Fig3. Plot for $(\log d) v s$. (Load P)

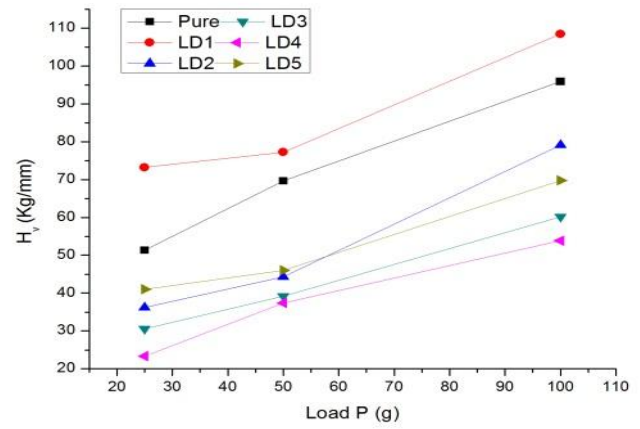

Fig4. Plot for hardness number $\left(H_{v}\right)$ vs. (Load P)

Table2. Work hardening coefficient (n)

\begin{tabular}{|c|c|c|c|c|}
\hline \multirow{2}{*}{ Samples } & \multicolumn{3}{|c|}{$\begin{array}{c}\text { Microhardness (Hv) for } \\
\text { the loads of }\end{array}$} & \multirow{2}{*}{$\begin{array}{c}\text { Work hardening } \\
\text { coefficient (n) }\end{array}$} \\
\cline { 2 - 4 } & $25 \mathrm{gm}$ & $50 \mathrm{gm}$ & $100 \mathrm{gm}$ & 3.63975 \\
\hline Pure NSH & 51.35 & 69.65 & 95.9 & 2.71564 \\
\hline $\begin{array}{c}\text { LD1(0.2mole\%of L- Lucine } \\
\text { doped NSH) }\end{array}$ & 73.25 & 77.25 & 108.5 & 4.05917 \\
\hline $\begin{array}{c}\text { LD2(0.4mole\% of L- Lucine } \\
\text { doped NSH) }\end{array}$ & 36.2 & 44.3 & 79.15 & 3.82799 \\
\hline $\begin{array}{c}\text { LD3(0.6mole\%of L- Lucine } \\
\text { doped NSH) }\end{array}$ & 30.55 & 39.15 & 60.15 & 3.82799 \\
\hline $\begin{array}{c}\text { LD4(0.8mole\% of L- Lucine } \\
\text { doped NSH) }\end{array}$ & 23.345 & 37.45 & 53.85 & 3.11084 \\
\hline $\begin{array}{c}\text { LD5(1 mole \% of L- Lucine } \\
\text { doped NSH) }\end{array}$ & 41.05 & 46.05 & 69.75 & 3.15 \\
\hline
\end{tabular}




\subsection{ELECRICAL STUDIES}

The AC electrical conductivity $(\sigma)$ was calculated byfollowing formula.

$$
\sigma=\varepsilon_{0} \varepsilon_{\mathrm{r}} \omega \tan \delta
$$

Where $\varepsilon_{0}$ is the permittivity for free space $\left(8.85 \times 10^{-12} \mathrm{C}^{2} \mathrm{~N}^{-1} \mathrm{~m}^{-2}\right)$ and $\omega$ is the angular frequency $(\omega=2 \pi f)$.

The dielectric constant $\left(\varepsilon_{\mathrm{r}}\right)$ was calculated by following formula



Where $\mathrm{A}_{\text {cry }}$ is the area of the crystal touching the electrode and $\mathrm{A}_{\text {air }}$ is the area of the electrode. The dielectric losses were determined all grown crystals by a method adopted by previous authors $[13,15]$. The $\varepsilon_{\mathrm{r}}$, tanסand $\sigma_{\mathrm{ac}}$ values obtained in the present study with different frequencies are shown in Figures 5-7.The $\varepsilon_{\mathrm{r}}$, tanסand $\sigma_{\mathrm{ac}}$ values obtained at $50^{\circ} \mathrm{C}$ with all the frequencies are provided in Table 3 . All the electrical parameters are found to increase with increasing temperature. This is normal dielectric behavior to metal sulphate. This can be understood on the basis of polarization. The electronic exchange of ions in the crystal gives electron displacement in the direction of electrical field, which leads to polarization.
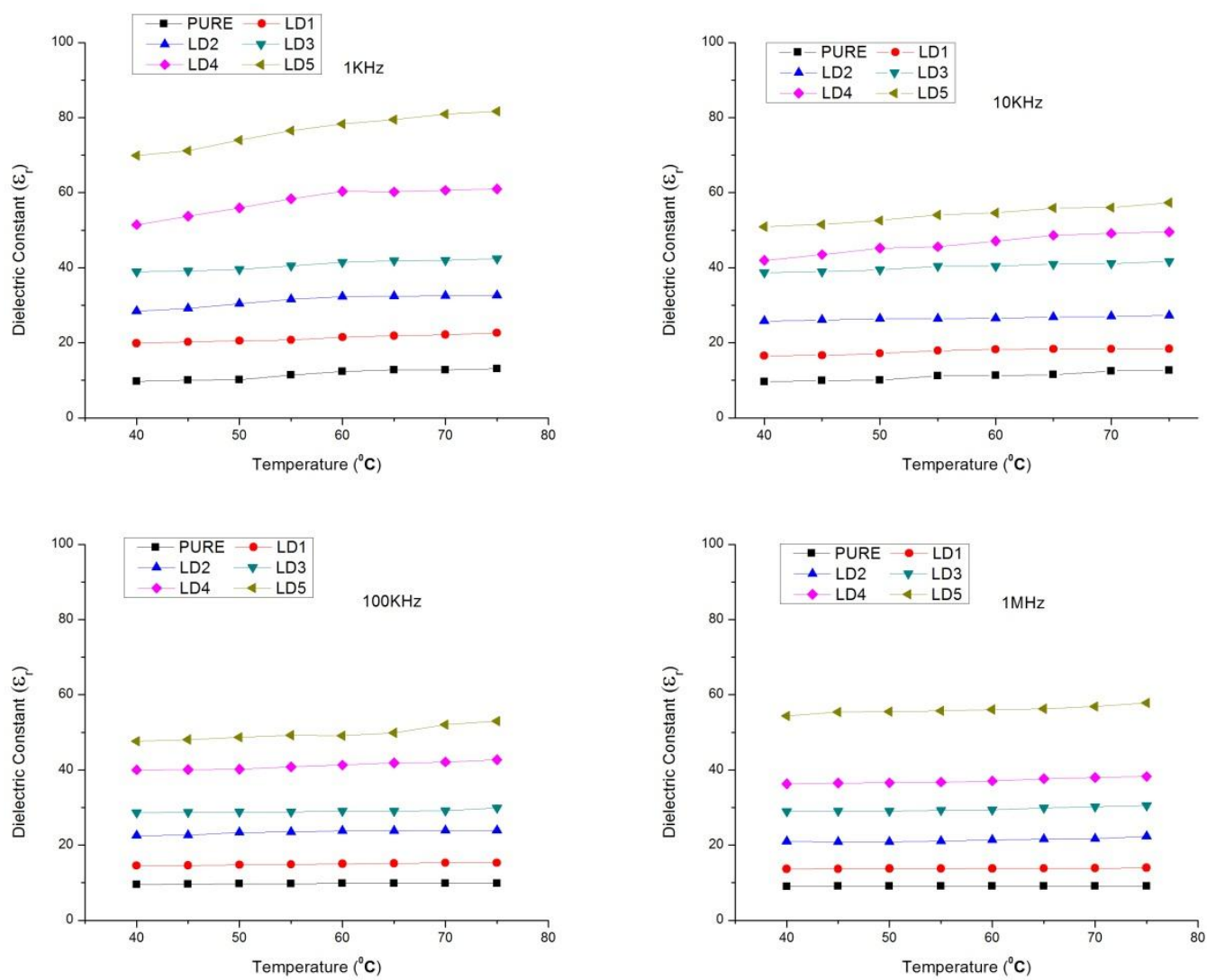

Fig5. The dielectric constants for pure and doped NSH 

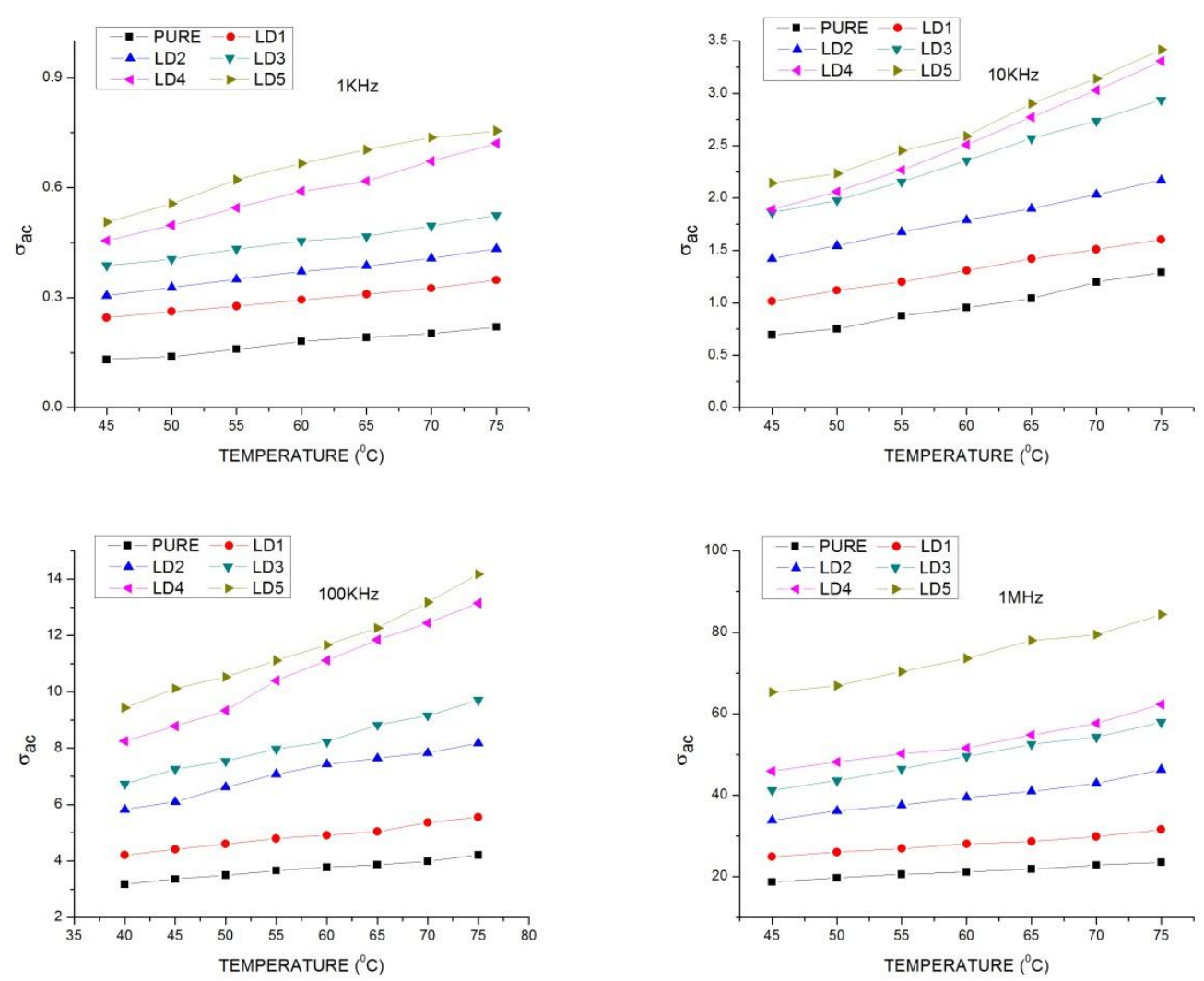

Fig6. The AC electrical conductivities $\left(x 10^{-6} \mathrm{mho} / \mathrm{m}\right)$ for pure and doped NSH crystal
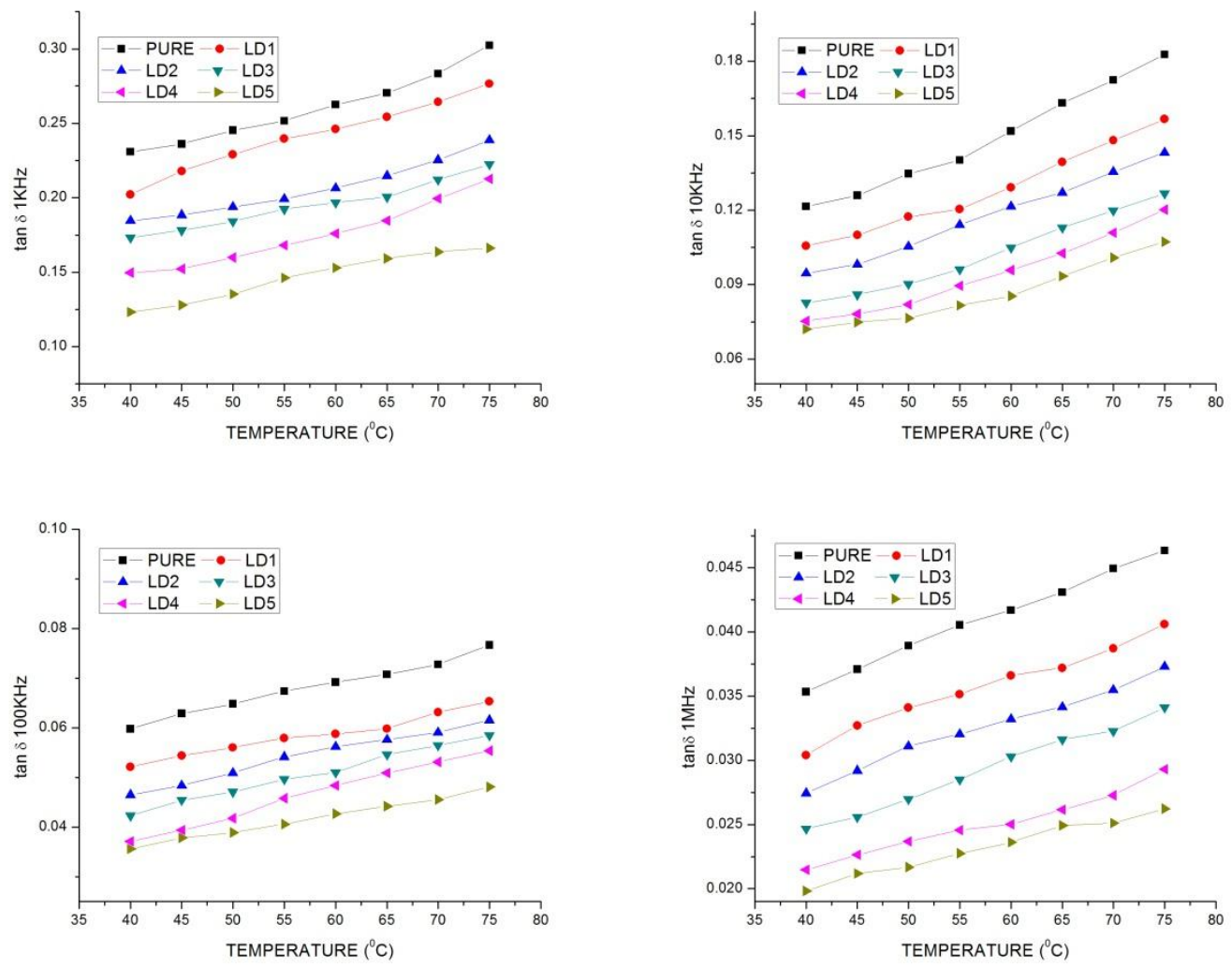

Fig7. The dielectric loss factors for pure and doped NSH crystals 
Table 3 - The $\varepsilon_{\mathrm{r}}$, tan $\delta$ and $\sigma_{\mathrm{ac}}\left(\mathrm{x} 10^{-6} \mathrm{mho} / \mathrm{m}\right)$ values at $50^{\circ} \mathrm{C}$ for pure and doped NSH.

\begin{tabular}{|c|c|c|c|c|c|}
\hline \multirow{2}{*}{ Samples } & \multirow{2}{*}{ Parameter } & \multicolumn{4}{|c|}{ With a frequency of } \\
\hline & & $1 \mathrm{KHz}$ & $10 \mathrm{KHz}$ & $100 \mathrm{KHz}$ & $1 \mathrm{MHz}$ \\
\hline \multirow{3}{*}{ Pure NSH } & $\varepsilon_{\mathrm{r}}$ & 10.157 & 10.040 & 9.705 & 9.095 \\
\hline & Tand & 0.245 & 0.135 & 0.065 & 0.039 \\
\hline & $\sigma_{\mathrm{ac}\left(\mathrm{x} 10^{-6} \mathrm{mho} / \mathrm{m}\right)}$ & 0.138 & 0.752 & 3.495 & 19.687 \\
\hline \multirow{3}{*}{ NSH+ LD1 } & $\varepsilon_{\mathrm{r}}$ & 20.565 & 17.165 & 14.787 & 13.756 \\
\hline & Tand & 0.229 & 0.117 & 0.056 & 0.034 \\
\hline & $\sigma_{\mathrm{ac}\left(\mathrm{x} 10^{-6} \mathrm{mho} / \mathrm{m}\right)}$ & 0.262 & 1.120 & 4.605 & 26.067 \\
\hline \multirow{3}{*}{$\mathrm{NSH}+\mathrm{LD} 2$} & $\varepsilon_{\mathrm{r}}$ & 30.426 & 26.400 & 23.395 & 20.881 \\
\hline & Tand & 0.194 & 0.105 & 0.051 & 0.031 \\
\hline & $\sigma_{\mathrm{ac}\left(\mathrm{x} 10^{-6} \mathrm{mho} / \mathrm{m}\right)}$ & 0.328 & 1.546 & 6.618 & 36.104 \\
\hline \multirow{3}{*}{$\mathrm{NSH}+\mathrm{LD} 3$} & $\varepsilon_{\mathrm{r}}$ & 39.594 & 39.441 & 28.834 & 29.064 \\
\hline & Tand & 0.184 & 0.090 & 0.047 & 0.027 \\
\hline & $\sigma_{\mathrm{ac}\left(\mathrm{x} 10^{-6} \mathrm{mho} / \mathrm{m}\right)}$ & 0.405 & 1.979 & 7.543 & 43.565 \\
\hline \multirow{3}{*}{ NSH+ LD4 } & $\varepsilon_{\mathrm{r}}$ & 55.969 & 45.211 & 40.167 & 36.585 \\
\hline & Tand & 0.160 & 0.082 & 0.042 & 0.024 \\
\hline & $\sigma_{\mathrm{ac}\left(\mathrm{x} 10^{-6} \mathrm{mho} / \mathrm{m}\right)}$ & 0.497 & 2.060 & 9.331 & 48.149 \\
\hline \multirow{3}{*}{$\mathrm{NSH}+\mathrm{LD} 5$} & $\varepsilon_{\mathrm{r}}$ & 73.972 & 52.603 & 48.688 & 55.532 \\
\hline & Tand & 0.135 & 0.076 & 0.039 & 0.022 \\
\hline & $\sigma_{\mathrm{ac}\left(\mathrm{x} 10^{-6} \mathrm{mho} / \mathrm{m}\right)}$ & 0.556 & 2.235 & 10.524 & 66.900 \\
\hline
\end{tabular}

\section{CONCLUSION}

Good quality crystals were grownsuccessfully by slow evaporation method. These are characterized by PXRD, mechanical and electrical measurements. The PXRD of spectra confirms the crystalline perfection of the grown crystals. Lattice parameters calculated from the XRD pattern of the pure and doped NSH crystals and determination of lattice volume indicate that the impurity molecules have entered in the crystal matrix of NSH. The hardness values of the crystals are varied with the dopants used and belong to the category of soft materials. The dielectric constants were found to increase with increasing temperature. The increase of AC conductivity with increase of temperature has been understood as essentially due to temperature dependence. The present study indicates that dopant L- Lucineleads to the discovery of promising low value dielectric materials. So it is more interesting that doped crystals are useful in micro electronic industry.

\section{REFERENCES}

[1] X. Wang, X. Zhuang, G. Su, Y. He, Opt. Mater. 31 (2008) 233.

[2] G. Su, X. Zhuang, Y. He, Z. Li, G. Wang, J. Phys. D: Appl. Phys. 35 (2002) 2652.

[3] R.Rajasekaran, R. Mohankumar, R. Jeyavel, P.Ramasamy, J. cryst.growth 252(2002)317.

[4] P.R. Newman, L.F. Warran, P. Cunningham, T.V. chang, D.E. Cooper, G.L Burdge, P.P Dingels, C. K. Lowema, mater. Res. Soc. Symp. Proc. 173 (1990)557.

[5] H. Youping, C. Jianrong, S. Genbo, XinsinZhuang, Guohui Lee, Rigong Jiang, J.Cryst. Growth 233 (2001) 809.

[6] G. Bhagavannarayana, S.K. Kushwah J. Appl. Cryst. 43 (2010) 154.

[7] P. Krishnan, K. Gayathri, G. Bhagavannarayana, V. Jayaramakrishnan,

S. Gunasekaran, G. Anbalagan, Spectrochim. Acta A:Mol. Biomol. Spectrosc.112 (2013) 152.

[8] K. Senthilkumar, S. MoorthyBabu, G. Bhagavannarayana, J. Appl. Cryst. 44 (2011) 313.

[9] K. Sangwal (1996) Prog.Cryst.Growth and Charact.

[10] H.Lipson, H. Steeple, Interpretation of X-ray Powder Diffraction Patterns, Macmillan, New York, 1970.

[11] S. Meenakshisundaram, S. Parthiban, N. Sarathi, R. Kalavathy, G. Bhagavannarayana, J. Cryst. Growth 293 (2006) 376-381.

[12] E.M. Onitsch, Mikroskopie 2 (1947) 131.

[13] S. Goma, C.M. Padma, C.K. Mahadevan, Mater. Lett. 60 (2006) 3701-3705.

[14] N.P. Rajesh, V. Kannan, P.S. Raghavan, P. Ramasamy, C.W. Lan, Mater. Lett. 52 (2002)326-328.

[15] J.L. Jones, K.W. Paschen, J.B. NicholsoJAppl Opt., vol. 2, pp.955-61, 1963 